\title{
AValiação do tamanho E PESO de PROPÁGulos das ESPÉCies PiONEIRAS de MANGUE NA FORMAÇÃO DE PLÂNTULAS PARA A RECUPERAÇÃo DE MANGUEZAIS
}

\author{
NeIlson Rocha da Silva ${ }^{1 *}$, Rafaela Camargo Maia ${ }^{2}$ \\ ${ }^{1}$ Mestre em Tecnologia e Gestão Ambiental pelo Instituto Federal de Educação, Ciência e Tecnologia do Ceará (IFCE). \\ ${ }^{2}$ Docente do Instituto Federal de Educação, Ciência e Tecnologia do Ceará (IFCE), Laboratório de Ecologia de Manguez̧ais, Acaraú, Ceará - Brasil, ORCID: \\ 0000-0001-5871-4610. \\ * Autorpara Correspondência: neilsonrocha@outlook.com.br
}

Recebido em 20 de abril de 2018. Aceito em 20 de dezembro de 2018. Publicado em 28 de dezembro de 2018.

\begin{abstract}
Resumo - As espécies de Laguncularia racemosa e Avicennia schaueriana são pioneiras, importantes no reflorestamento de áreas degradadas de manguezal. Neste contexto, o objetivo deste trabalho foi avaliar o tamanho e peso dos propágulos das espécies Laguncularia racemosa e Avicennia schaueriana na germinação e formação de plântulas mais vigorosas para produção de mudas. O experimento foi conduzido no Instituto Federal do Ceará, localizado no município de Acaraú no estado do Ceará. Em Laboratório, os propágulos passaram por assepsia, foram triadas por dimensões e sanidade, totalizando 3 grupos com 10 propágulos de cada espécie. Os propágulos foram semeados em embalagens retangular de polietileno transparente, o substrato utilizado foi areia lavada e o experimento foi conduzido em condições ambiente. Foram realizadas análises da porcentagem de germinação, Índice de velocidade de germinação e Índice de qualidade de Dickson. Os resultados permitiram concluir que o tamanho e peso dos propágulos de Laguncularia racemosa e Avicennia schaueriana de maior peso e tamanho formaram plântulas mais vigorosas, uma característica importante de mudas para reflorestamento.
\end{abstract}

Palavras-chave: Mudas florestais; Recuperação de manguezais; Reflorestamento; vigor de Plântulas.

Evaluation of SIZE AND WEIGHT OF POTENTIAL PROPERTIES OF MANGUE SPECIES IN THE FORMATION OF SEEDS FOR THE RECOVERY OF MANGROVE

Abstract - The species of Laguncularia racemosa and Avicennia schaueriana are pioneers, important in the reforestation of degraded areas of mangrove. In this context, the objective of this work was to evaluate the size and weight of the propagules of the species Laguncularia racemosa and Avicennia schaueriana in the germination and formation of more vigorous seedlings for seedling production. The experiment was conducted at the Instituto Federal do Ceará, located in the municipality of Acaraú in the state of Ceará. In laboratory, the propagules underwent asepsis, were sorted by size and sanity, totalizing 3 groups with 10 propagules of each species. The propagules were seeded in rectangular transparent polyethylene packages, the substrate used was sand washed and the experiment was conducted under ambient conditions. The germination percentage, the germination speed index and the Dickson quality index were analyzed. The results allowed to conclude that the size and weight of Laguncularia racemosa and Avicennia schaueriana propagules of greater weight and size formed more vigorous seedlings, an important characteristic of seedlings for reforestation.

KeYwORDS: FOREST SAPLINGS; MANGROVE RECOVERY; REFORESTATION; VIGOR OF SEEDLINGS. 
Evaluación DEL TAMAÑo Y PESO DE PROPÁGULOS DE LAS ESPECIES PIONERAS DE MANGUE EN LA FORMACIÓN DE PLÁNTULAS PARA LA RECUPERACIÓN DE MANGLARES

Resumen - Las especies de Laguncularia racemosa y Avicennia schaueriana son pioneras, importantes en la reforestación de áreas degradadas de manglares. En este contexto, el objetivo de este trabajo fue evaluar el tamaño y peso de los propágulos de las especies Laguncularia racemosa y Avicennia schaueriana en la germinación y formación de plántulas más vigorosas para producción de mudas. El experimento fue conducido en el Instituto Federal de Ceará, ubicado en el municipio de Acaraú en el estado de Ceará. En Laboratorio, los propulsados pasaron por asepsia, fueron triados por dimensiones y sanidad, totalizando 3 grupos con 10 propágulos de cada especie. Los plantones fueron sembrados en envases rectangular de polietileno transparente, el sustrato utilizado fue arena lavada y el experimento fue conducido en condiciones ambiente. Se realizaron análisis del porcentaje de germinación, Índice de velocidad de germinación e Indice de calidad de Dickson. Los resultados permitieron concluir que el tamaño y peso de los propulsores de Laguncularia racemosa y Avicennia schaueriana de mayor peso y tamaño formaron plántulas más vigorosas, una caracteristica importante de mudas para reforestación.

Palabras clave: Mudas forestales; Recuperación de manglares; Reforestación; vigor de Plántulas.

\section{INTRODUÇÃO}

O manguezal é um ecossistema litorâneo que ocorre em terrenos baixos, sujeitos à ação das marés, às quais se associa, predominantemente, a vegetação natural conhecida como mangue (Brasil 2012). É protegido pelo Código Florestal (Lei n 12.651 de 2012), que o considera, em toda a sua extensão, como Área de Preservação Permanente (APP) (Brasil 2012).

Ainda assim, mesmo protegido por lei, os ecossistemas de manguezais tem sido degradados, devido várias alterações vinculadas aos efeitos setor industrial, desenvolvimento urbano, barragem de rios, aquicultura, agropecuária, lançamento de resíduos sólidos, lixão, produção de sal, aterros visando a construção civil, turismo entre outros, além do desmatamento direto das florestas (Camargo et al. 2004; Maia 2005; Nanni e Nanni 2005; Waycott et al. 2009; Junior 2011).

Por se tratar de um ecossistema com características específicas, ao se trabalhar com a recuperação destes ambientes, deve-se conhecer seu processo sucessional, a composição florística e estrutura típica de cada estágio (Almeida 2016). Para as operações de reflorestamento, sugere-se primeiro o plantio das pioneiras, seguido das secundárias iniciais, secundárias tardias e as climácicas (Lima 2004). E quanto maior for o nível de degradação na área, deve-se utilizar uma maior densidade de espécies pioneiras (Almeida 2016).

A floresta do manguezal possui poucas espécies arbóreas, no Brasil, ocorrem seis espécies vegetais verdadeiras. Sendo identificadas como pioneiras, as espécies Avicennia schaueriana Stapf e Leechm ex Moldenke e Laguncularia racemosa (L.) Gaertn. f. em processos de colonização ou regeneração de manguezais (Soares et al. 2008; Calegario 2012). Segundo Bernini e Rezende (2003), Laguncularia racemosa se estabelecem em áreas abertas, seguida pelo gênero Avicennia e posteriormente por Rhizophora no processo sucesssional.

Entretanto, mesmo havendo conhecimento dos processos sucessionais e da importância do reflorestamento de áreas degradadas, existem poucos trabalhos voltados para a produção de mudas de espécies florestais do manguezal, principalmente com as pioneiras. Trabalhos relacionados a produção de mudas são importantes, pois o sucesso das mudas em campo, depende da capacidade de suportar os estresses ambientais pós-plantio. Segundo Gonçalves et al. (2005), as mudas devem apresentar vigor, sistema radicular formado, adequado aspecto fitossanitário, rustificação entre outros parâmetros.

O vigor das mudas em viveiro florestais é um dos parâmetros chave na seleção de plântulas (São Paulo e Sema 2014). O tamanho e peso das sementes são variáveis importantes que influência o vigor das plântulas, assim, as 
análises realizadas em sementes florestais, principalmente de espécies nativas, têm como principal objetivo avaliar a porcentagem de germinação e o vigor da espécie (São Paulo e Sema 2014).

As sementes das espécies de Laguncularia racemosa e Avicennia schaueriana, na literatura, são denominadas de propágulos, uma vez que são espécies vivíparas, e possuem variações no tamanho e peso (Sousa et al. 2003; Purnobasuk e Utami 2016). Com isso, a avaliação das sementes por peso e tamanho pode ser uma maneira eficiente de melhorar a qualidade de lotes de sementes em relação à uniformidade de emergência, tamanho e vigor das plântulas (Pedron et al. 2004).

Para muitas espécies vegetais, as sementes maiores ou de maior densidade em uma mesma espécie são, potencialmente, mais vigorosas do que as menores e menos densas e originam plântulas mais desenvolvidas (Carvalho e Nakagawa 2000). A densidade e o tamanho de sementes, de forma conjunta ou isolada, aliada a adequadas condições meteorológicas, fitossanitárias e nutricionais, são de grande importância para o bom desenvolvimento das plantas (Amaral 2010).

Neste contexto, o presente trabalho testa a hipótese que há diferença na formação de plântulas para mudas florestais devido a variação do tamanho e peso de propágulos de mangue. Com isto, o objetivo deste trabalho foi avaliar o tamanho e peso dos propágulos das espécies Laguncularia racemosa e Avicennia schaueriana na germinação e formação de plântulas mais vigorosas para a produção de mudas.

\section{MATERial e método}

Área de estudo e coleta de Propágulos

O experimento foi conduzido no Instituto Federal do Ceará - Campus Acaraú $\left(-2.889037^{\circ} \mathrm{S}\right.$ e $\left.40.113054^{\circ} \mathrm{W}\right)$, localizado no município de Acaraú no estado do Ceará, com início no dia 15 de maio e finalizado no dia 19 de junho de 2017. Os propágulos foram coletadas no dia 14 de maio de 2017, no manguezal próximo da vila do Curral Velho no município de Acaraú - CE $\left(-2.889037^{\circ} \mathrm{S}\right.$ e $\left.-40.077642^{\circ} \mathrm{W}\right)$, considerado uma área menos impactada por ações antrópicas, por meio de imagens de satélite do Google Earth Pro e observações visuais de campo da fauna, flora e solo. Essa área também foi considerada conservada devido ao trabalho de Meireles et al. (2007), que relatam de maneira geral, que o mangue sapateiro ou vermelho (Rhizophora mangle) chega a 20 metros de altura nas áreas mais conservadas e ao trabalho de Pompei et al. (2014), que trabalha com as percepções da comunidade do Curral Velho sobre os serviços ecossistêmicos do manguezal.

\section{Procedimentos em laboratório}

No Laboratório de Ecologia de Manguezais (ECOMANGUE), os propágulos foram lavados em água corrente, imersos em solução hipoclorito de sódio $(\mathrm{NaClO})$ a 1\% (um por cento) durante 5 min (cinco minutos) e posteriormente lavadas em água corrente para a desinfecção. A solução de $\mathrm{NaClO}$ é bastante utilizada em assepsia de uma ampla variedade superfícies (Kikuti et al. 2005; Muniz et al. 2007; Pinho 2012; Srey et al. 2013). Pereira et al. (2009) obtiveram maior eficiência na desinfestação e estabelecimento in vitro de explantes de bananeira 'IAC 2001' com concentrações de hipoclorito de sódio a 1\%.

Os propágulos foram triados por tamanho (dimensão de comprimento e largura) e sanidade aparente (infestação e injúrias por insetos e incidência de fungos). Foram selecionados 60 propágulos, 30 propágulos de cada espécie, dividido em 3 grupos com 10 propágulos (Tabela 1) e semeados a uma profundidade de $0,5 \mathrm{~cm}$, em embalagens retangular de polietileno transparente com dimensões de 15 x 23 x $10 \mathrm{~cm}$. 
Tabela 1 - Dados estruturais dos propágulos de Laguncularia racemosa e Avicennia schaueriana testados no experimento.

\begin{tabular}{ccccc}
\hline Espécie & Grupos & $\begin{array}{c}\text { Variação do } \\
\text { comprimento }(\mathbf{m m})\end{array}$ & $\begin{array}{c}\text { Variação da } \\
\text { 1argura }(\mathbf{m m})\end{array}$ & $\begin{array}{c}\text { Peso do grupo } \\
\text { de sementes }(\mathbf{g})\end{array}$ \\
\hline \multirow{3}{*}{ Laguncularia racemosa } & 1 & 11,0 à 12,5 & 5 à 5,5 & 2,4702 \\
& 2 & 14,5 à 15,0 & 5 & 2,6437 \\
\hline \multirow{3}{*}{ Avicennia schaueriana } & 3 & 18,0 à 19,5 & 4 à 6 & 3,8949 \\
& 1 & 17,0 à 18,0 & 16,0 à 17,0 & 11,8485 \\
& 2 & 20,5 à 22,0 & 17,0 à 21,5 & 16,3235 \\
\hline
\end{tabular}

O substrato utilizado foi areia lavada, pois Guerrero et al. (1992) testaram a germinação de propágulos de mangue em diferentes substratos, como terriço do solo de mangue, serragem, areia de rio e pélete de arroz, obtendo melhores resultados com o substrato proveniente de areia do rio com 98,61\% de germinação.

A areia lavada foi depositada em recipiente de polietileno, com uma camada de $7 \mathrm{~cm}$. O recipiente possuía apenas um dreno, assim, o substrato era saturado com água doce às $8 \mathrm{~h}$ da manhã e drenado lentamente, permanecendo em capacidade de campo entre às 12 e $16 \mathrm{~h}$, e às $17 \mathrm{~h}$ o substrato era saturado novamente. $\mathrm{O}$ experimento foi conduzido em condições meteorológicas ambiente, com temperatura média de $26,35^{\circ} \mathrm{C}$; umidade relativa de $82,01 \%$ e radiação de $829,74 \mathrm{KJ} / \mathrm{m}^{2}$ (INMET 2017).

Ao final do experimento, foram coletados dados estruturais de altura $(\mathrm{H})$, diâmetro do coleto (DC) e tamanho da raiz, além do peso da matéria fresca de três exemplares aleatórios de cada grupo. Posteriormente, foram separados a parte aérea da parte do sistema radicular e desidratados a $60^{\circ} \mathrm{C}$ durante $20 \mathrm{~h}$ em estufa de secagem, para obtenção de matéria seca da raiz, da parte aérea e da matéria seca total.

$\mathrm{Na}$ obtenção de dados estruturais foi utilizado um paquímetro para o tamanho do propágulo e DC das plântulas, régua graduada em centímetros para $\mathrm{H}$ e tamanho da raiz e para o peso do propágulo, da matéria fresca, matéria seca da raiz e matéria seca parte aérea foi utilizada balança de precisão (SHIMADZU AY220) com precisão de 0,0001gr.

\section{Análise dos dados}

Foram realizadas as seguintes análises de dados:

- Porcentagem de germinação $(G)$, fórmula:

$$
\mathrm{G}=\frac{\text { Número de propágulos germinados x } 100}{\text { Número de propágulos semeados }}
$$

- Índice de velocidade de germinação (IVG) (Maguire 1962), fórmula:

$$
\text { IVG }=\frac{\text { Número de propágulos germinados }}{\text { Tempo de germinação em dias }}
$$

- Índice de qualidade de Dickson (IQD) (Dickson, Leaf e Hosner 1960), fórmula:

$$
\mathrm{IQD}=\frac{\text { Matéria seca total }}{\left(\frac{\mathrm{H}+\mathrm{DC}+\text { matéria seca da parte aérea }}{\text { Matéria seca da raiz }}\right)}
$$


Análise de Variância (ANOVA) para comparar as variações estruturais das plântulas (Altura, diâmetro do coleto e tamanho da raiz) e peso da matéria fresca e seca da raiz, parte aérea e total da plântula, sendo exibidos apenas variações significativas. Assim, apresentando significância de 5\%, os dados foram submetidos ao Teste de Tukey para verificação dos contrastes entre os grupos de propágulos e aspectos morfológicos.

\section{RESUltados E Discussão}

As espécies Laguncularia racemosa e Avicennia schaueriana apresentaram variações intraespecíficas no tamanho e peso dos propágulos utilizados no experimento. Resultados semelhantes foram observados por Kennedy e Mitchel (2003), que investigaram a influência do tamanho do propágulo e o dano provocado por artrópodes no estabelecimento e crescimento precoce das espécies Avicennia germinans, Laguncularia racemosa e Rhizophora mangle em manguezal da costa caribenha do Panamá. Neste trabalho, embora tenha sido observada uma variação do tamanho e peso, os propágulos tiveram alta taxa de geminação, variando de 80\% à 100\% (Tabela 2). Segundo Sousa et al. (2003), o tamanho dos propágulos também não afetaram as taxas de estabelecimento de plântulas, assim como Purnobasuki e Utami (2016) e Finney (2011), que não observaram diferença significativa na taxa de germinação total de diferentes tamanhos de propágulos de Avicennia marina (Forsk) Vierh e Avicennia germinas.

Tabela 2 - Resultados da média da dimensão (Dim), matéria fresca (M. fresca), tempo de germinação em dias (Tempo G), germinação (G), índice de velocidade de germinação (IVG) e índice de qualidade de Dickison (IQD) das espécies Laguncularia racemosa e Avicennia schaueriana.

\begin{tabular}{cccccccc}
\hline Espécie & Grupo & Dim. $(\mathbf{m m})$ & M. fresca $(\mathbf{g})$ & Tempo G & G (\%) & IVG & IQD \\
\hline \multirow{2}{*}{$\begin{array}{c}\text { Laguncularia } \\
\text { racemosa }\end{array}$} & 1 & $12,00 \times 5,00$ & 2,4702 & 14 & 100 & 0,6666 & 0,0007 \\
\cline { 2 - 8 } & 2 & $14,83 \times 5,16$ & 2,6437 & 14 & 100 & 0,6666 & 0,0026 \\
\cline { 2 - 8 } & 3 & $18,50 \times 5,00$ & 3,8949 & 14 & 80 & 0,5333 & 0,0024 \\
\hline \multirow{2}{*}{$\begin{array}{c}\text { Avicennia } \\
\text { schaueriana }\end{array}$} & 1 & $17,33 \times 16,50$ & 11,8485 & 17 & 100 & 0,5882 & 0,0206 \\
\cline { 2 - 8 } & 2 & $21,16 \times 19,33$ & 16,3235 & 35 & 100 & 0,2857 & 0,0275 \\
\hline
\end{tabular}

Os grupos de propágulos 1 e 2 da espécie Laguncularia racemosa apresentaram 100\% de germinação e com índice de velocidade de germinação iguais (Tabela 2). Já o grupo 3 teve dois indivíduos com paralização do processo de germinação, provavelmente devido a necrose das raízes secundárias, como pode ser visto na Figura 1. Assim, contendo oito indivíduos com germinação completa, foi considerado 80\% de germinação e com menor índice de velocidade de germinação.

Figura 1 - Necrose das raízes secundárias da espécie Laguncularia racemosa durante a germinação.

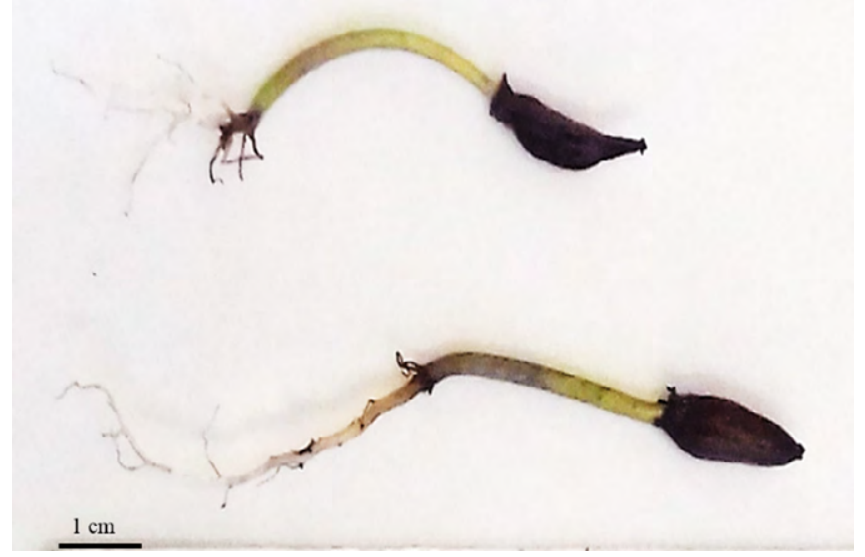


A espécie Avicennia schaueriana apresentou melhor índice de velocidade de germinação com propágulos de menor matéria fresca (Grupo 1). Contudo, os propágulos de Avicennia schaneriana e Laguncularia racemosa apresentaram alta taxa de germinação e velocidade de germinação (Tabela 1). A temperatura ambiente com média de $26,35^{\circ} \mathrm{C}$ (Quadro 1) no período de germinação pode ter contribuído para tal resultado. Segundo Oliveira (2005), a alta velocidade de germinação para estas espécies estão entre temperaturas de 15 e $35^{\circ} \mathrm{C}$ para Laguncularia racemosa e de 20 a $30^{\circ} \mathrm{C}$ para Avicennia schaueriana. A irrigação com água doce também pode ter contribuído para a alta taxa de germinação, pois a taxa de germinação pode ser inversa a concentração de sal, havendo menor germinação de espécies de mangue com aumento da salinidade (Cavalcanti et al. 2007), podendo ocasionar mortalidade das espécies menos tolerantes (Hossain et al. 2014).

O índice de qualidade de Dickson é um bom indicador da qualidade das mudas, pois no seu cálculo são considerados a robustez e o equilíbrio da distribuição da biomassa na muda, ponderando os resultados de vários parâmetros importantes empregados para avaliação da qualidade (Fonseca et al., 2002). Neste trabalho, o Índice de qualidade de Dickson mostrou que propágulos de peso maior tanto de Laguncularia racemosa como Avicennia schaueriana são os mais indicados para a produção de mudas (Tabela 2), formando plântulas com maior qualidade. Segundo Turnbull et al. (1999), as espécies com maior massa de semente são mais capazes de estabelecer e sobreviver sob uma ampla variação de condições.

O peso dos propágulos de Laguncularia racemosa tive interação significativa com o tamanho da raiz, matéria fresca da plântula, matéria seca da raiz e matéria seca da parte aérea (Tabela 3). Já o peso dos propágulos de Avicennia schaueriana apresentaram diferença significativa com a altura, matéria fresca total, matéria seca total, matéria seca da parte aérea e matéria seca da raiz (Tabela 4).

Tabela 3 - Resultados da análise de variância unidirecional (ANOVA) conduzida entre diferentes parâmetros morfológicos das mudas: tamanho da raiz $(\mathrm{cm})$; matéria fresca total $(\mathrm{g})$; peso seco das raízes $(\mathrm{g})$; peso seco da parte aérea (g) e o peso dos grupos do propágulo de Laguncularia racemosa. Onde $\mathrm{SS}=$ soma dos quadrados sequenciais, $\mathrm{DF}=$ grau de liberdade, $\mathrm{MS}=$ quadrados médios, $\mathrm{F}=$ valor de variância $\mathrm{e} P=$ evidência contra a hipótese nula.

\begin{tabular}{|l|c|c|c|c|c|}
\hline \multicolumn{1}{|c|}{ Parâmetros } & SS & DF & MS & F & P \\
\hline Tamanho da raiz & 10,380 & 2 & 5,191 & 8,111 & $0,020^{*}$ \\
\hline Matéria fresca total & 0,153 & 2 & 0,076 & 6,723 & $0,029^{*}$ \\
\hline Matéria seca da raiz & 0,013 & 2 & 0,006 & 11,750 & $0,008^{*}$ \\
\hline Matéria seca aérea & 0,003 & 2 & 0,001 & 16,050 & $0,004^{*}$ \\
\hline
\end{tabular}

*significativo a $5 \%$.

Tabela 4 - Resultados da análise de variância unidirecional (ANOVA) realizado entre diferentes parâmetros morfológicos das mudas: matéria fresca total em grama; peso seco das raízes (g); peso seco da parte aérea (g); altura da parte aérea $(\mathrm{cm})$; matéria seca total $(\mathrm{g})$ e o peso dos grupos do propágulo de Avicennia schaueriana. Onde SS = soma dos quadrados sequenciais, $\mathrm{DF}=$ grau de liberdade, $\mathrm{MS}=$ quadrados médios, $\mathrm{F}=$ valor de variância e $\mathbf{P}=$ evidência contra a hipótese nula.

\begin{tabular}{|l|c|c|c|c|c|}
\hline \multicolumn{1}{|c|}{ Parâmetros } & SS & DF & MS & F & P \\
\hline Altura da parte aérea & 2,936 & 2 & 1,468 & 17,61 & $0,003^{*}$ \\
\hline Matéria fresca total & 2,636 & 2 & 1,318 & 20,78 & $0,002^{*}$ \\
\hline Matéria seca da raiz & 0,084 & 2 & 0,042 & 14,13 & $0,005^{*}$ \\
\hline Matéria seca aérea & 0,006 & 2 & 0,003 & 18,01 & $0,003^{*}$ \\
\hline Matéria seca total & 0,137 & 2 & 0,068 & 17,10 & $0,003^{*}$ \\
\hline
\end{tabular}

*significativo a $5 \%$. 
Os propágulos de menor peso (Grupo1) de Laguncularia racemosa tiveram maior ganho de matéria seca da parte aérea, diferenciando significativamente dos propágulos maiores (Grupos 2 e 3). O grupo 2 diferenciou-se dos demais em matéria fresca total, entretanto não se diferenciou do grupo 3 em tamanho da raiz e matéria seca da raiz (Figura 2).

Figura 2 - Diferença significativa da matéria seca da raiz, matéria seca da parte aérea, tamanho da raiz e matéria fresca total por peso dos propágulos de Laguncularia racemosa, com média e erro padrão.
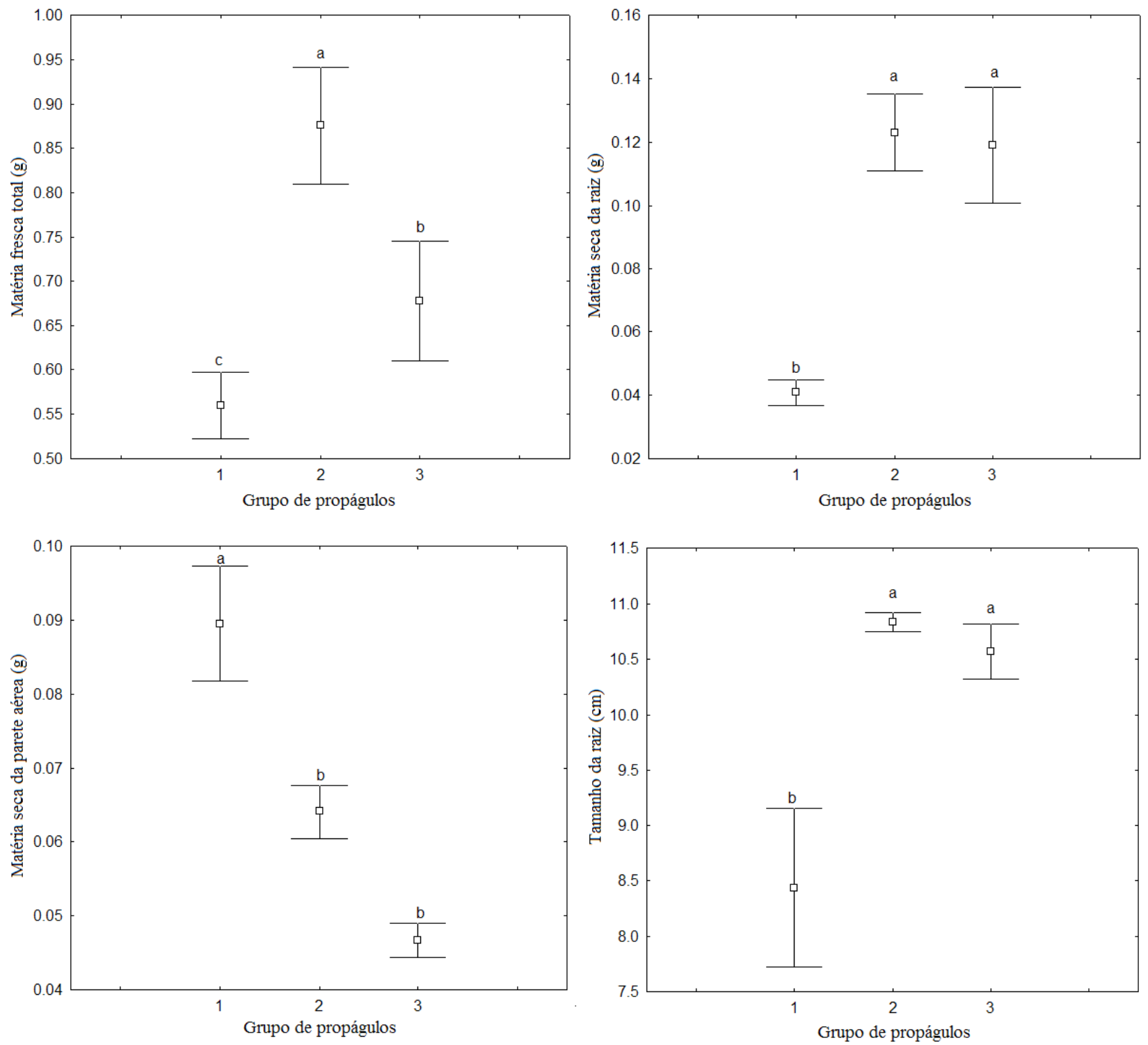

Os propágulos maiores (Grupo 3) da espécie Avicennia schaueriana se diferenciaram significativamente dos outros grupos de propágulos menores, para os parâmetros de matéria seca da raiz, matéria seca da parte aérea, matéria fresca total, altura e matéria seca total. Os grupos 1 e 2 não se diferenciaram significativamente em nenhum dos parâmetros analisados (Figura 3 e 4). 
Figura 3 - Diferença significativa do grupo $3 \mathrm{em}$ altura e matéria fresca total por peso dos propágulos de Avicennia schaueriana, com média e erro padrão.
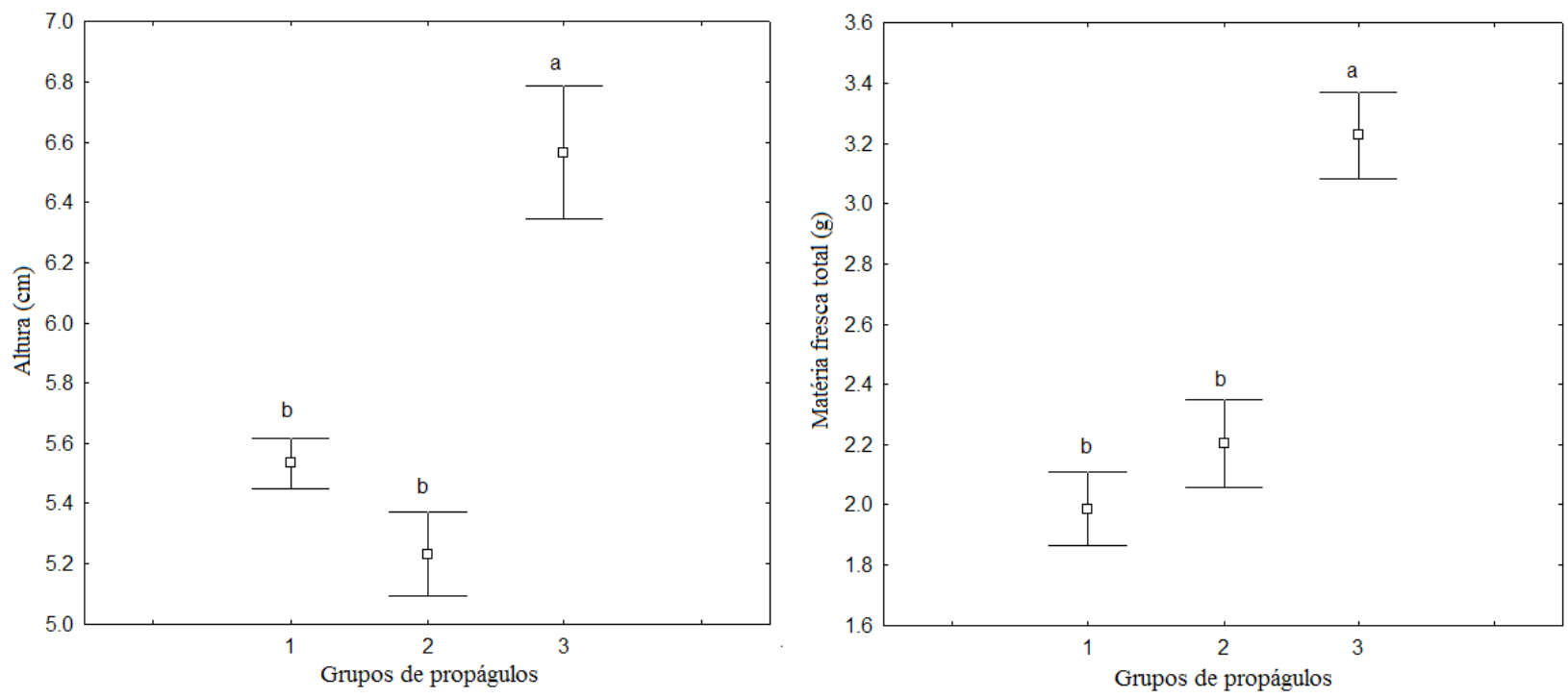

Figura 4 - Diferença significativa do grupo 3 em matéria seca da raiz, matéria seca da parte aérea e matéria seca total por peso dos propágulos de Avicennia schaueriana, com média e erro padrão.
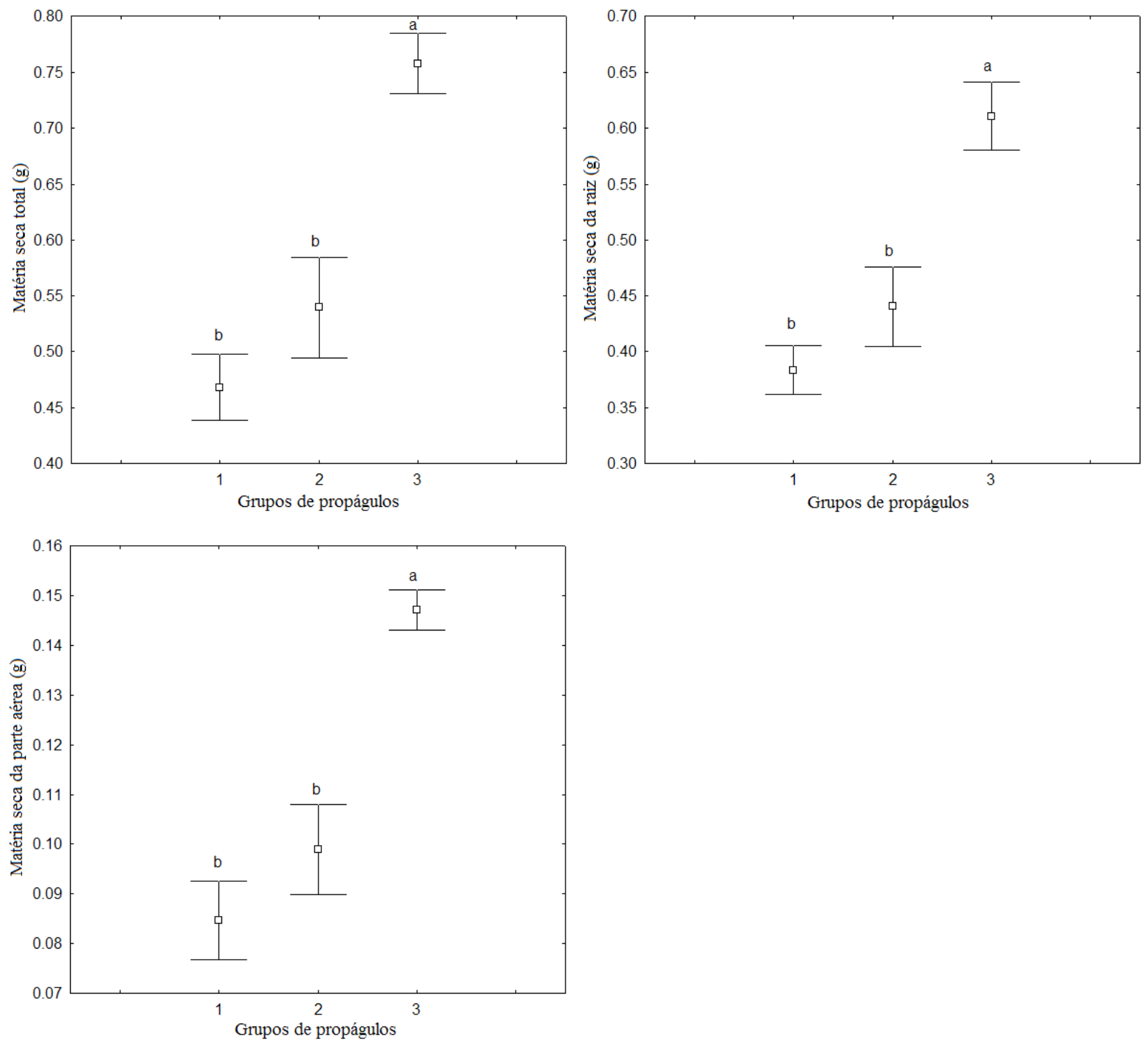
Os propágulos de Laguncularia racemosa com menor peso (grupo 1) tiveram menor tamanho de raiz, matéria fresca total e matéria seca da raiz, exceto a matéria seca da parte aérea, que foi maior, sendo o oposto observado no grupo 2, com peso de propágulos intermediário. Isso também foi observado nos propágulos da Avicennia schaueriana, porém para grupos extremos de menor e maior peso de propágulos (Grupos 1 e 3). As espécies com sementes de massa menor tendem a se dispersar melhor, geram mudas menores, dessa maneira, o aumento da massa das sementes tem sucesso na dispersão pela germinação e estabelecimento (Skarpaas et al. 2011).

Rycka et al. (2012) analisaram as estratégias de dispersão dos propágulos de Ceriops tagal (Perr.) C.B. Rob. (tamanho menor) e Rhizophora mucronata var. alokii (tamanho maior) em Gazi Bay na costa queniana, constatando que propágulos maiores possuem uma maior quantidade imediata de água e nutrientes apresentando uma maior probabilidade de estabelecimento devido ao seu grande tamanho, mais reservas de amido e crescimento de raiz mais rápido, sendo mais propensos a estabelecer com sucesso.

Segundo Sousa, Kennedy e Mitchel (2003) o tamanho do propágulo, por meio da sua influência no desempenho das mudas, pode afetar a taxa e o curso da regeneração após perturbação. Uma vantagem de tamanho precoce de plântulas, provenientes de propágulos com peso maior, poderia fazer uma grande diferença na sua resiliência, uma vez que durante o auto desbaste natural, as plântulas maiores se sobressaem as menores em crescimento e sobrevivência (Sousa, Kennedy e Mitchel 2003).

Com a necessidade cada vez maior de produzir mudas com características para sobreviver às condições adversas encontradas nas áreas dos reflorestamentos, e crescer satisfatoriamente, tem-se exigido um maior controle de qualidade das mesmas (Genro, 2004). Neste sentido, os propágulos de maiores tamanhos e pesos desenvolvem plântulas de mangue de maior qualidade para o reflorestamento de manguezais.

Reiterando que a regeneração de manguezais degradados depende da conjunção de probabilidades de aportes de propágulos e sobrevivência de plântulas, uma vez que a capacidade de propagação vegetativa das espécies de mangue é limitada (Tomlinson 2016). E tendo como uma das técnicas mais utilizada nos reflorestamentos de manguezais a retirada de plantas jovens de um determinado local do manguezal (transplante), onde há abundância de mudas (Projeto Uçá, 2015). Torna-se importante a seleção de propágulos para a produção de mudas em viveiros florestais, dando subsídio a maior taxa de pegamento em campo.

Diante do exposto, este trabalho traz a possibilidade de selecionar propágulos adequados para a produção de mudas em viveiro florestal, propiciando o aumento da taxa de adaptabilidade destas em campo. Uma vez que, o transplante de mudas de um mangue para uma área degradada pode ocasionar danos ao sistema radicular e deixar a raiz nua, sem torrão, sendo que, uma das principais indicações para sucesso do pegamento da muda é um sistema radicular de qualidade e com torrão (Huber 2004; Casasco, Santos e Quiñones 2014; Paludo e Klonowski 2018).

Visto isso, propágulos de maior tamanho e peso geram plântulas com sistema radicular mais desenvolvido e quando produzidos em viveiro florestal garantem o torrão aderido à raiz. Assim, as espécies trabalhadas no presente estudo, apresentam potencial para reflorestamento de áreas de manguezal impactados quando induzidas a recomposição dessas espécies pioneiras, por meio de semeadura ou transplante de mudas de maior vigor, na área que se pretende trabalhar.

\section{Conclusão}

Não houve diferença em dias totais de germinação para a espécie Laguncularia racemosa, porém foi observado uma diferença na porcentagem e índice de velocidade de germinação, devido a dormência no processo de germinação do grupo 3 de propágulo maiores e mais pesados.

Já para Avicennia schaueriana houve variações nos dias totais de germinação, com porcentagem de germinação total igual para todos os grupos e melhor índice de velocidade de geminação para propágulos menores. 
Os propágulos de Laguncularia racemosa com peso médio de massa fresca igual a 0,26 g (Dimensão de 14,83 x $5,16 \mathrm{~mm}$ ) por unidade de indivíduo foram os mais indicados para produção de mudas mais vigorosas.

Para a espécie Avicennia schaueriana são indicadas propágulos maiores com peso médio de massa fresca individual de 2,53 g (Dimensão de 24,16 x $22 \mathrm{~mm}$ ), para produção de mudas mais vigorosas.

Os propágulos de Laguncularia racemosa e Avicennia schaueriana de maior peso e tamanho formaram plântulas mais vigorosas, um característica importante de mudas para reflorestamento.

\section{REFERÊNCIAS BIBLIOGRÁFICAS}

Almeida DS. 2016. Recuperação ambiental da Mata Atlântica. $3^{a}$ edição, 200p, Editus. Ilhéus, BA. DOI: https://doi. org/10.7476/9788574554402.

Amaral AD. 2010. Qualidade de sementes de Canola classificadas por densidade em diferentes condições de déficit hídrico e de profundidade de semeadura. 2010. 61 f. Dissertação (Mestrado em Agronomia) - Universidade Federal de Santa Maria. Santa Maria/RS.

Bernini E, Rezende CE. 2004. Estrutura da vegetação em florestas de mangue do estuário do rio Paraíba do Sul, Estado do Rio de Janeiro, Brasil. Acta Botanica Brasilica, Belo Horizonte, v. 18, n. 3, p. 491-502. DOI:http://dx.doi.org/10.1590/ S0102-33062004000300009.

Brasil. 2012. Lei $\mathbf{n}^{\mathbf{0}} \mathbf{1 2 . 6 5 1}$, de 25 de maio de 2012. Dispõe sobre a proteção da vegetação nativa; altera as Leis nos 6.938, de 31 de agosto de 1981, 9.393, de 19 de dezembro de 1996, e 11.428, de 22 de dezembro de 2006; revoga as Leis nos 4.771, de 15 de setembro de 1965, e 7.754, de 14 de abril de 1989, e a Medida Provisória no 2.166-67, de 24 de agosto de 2001; e dá outras providências. Disponível em < http://www.planalto.gov.br/ccivil_03/_ato2011-2014/2012/lei/L12651compilado. htm>. Acessado em 06 de fevereiro de 2017.

Calegario G. 2012. Aspectos estruturais da vegetação do manguezal do estuário do Rio São João, RJ. Dissertação (Mestrado em Ecologia e Recursos Naturais) - Universidade Estadual do Norte Fluminense Darcy Ribeiro. Campos dos Goitacazes - RJ.

Cavalcanti VF, Andrade ACS, Soares MLG. 2007. Germination of Avicennia schaueriana and Laguncularia racemosa from two physiographic types of mangrove forest. Aquatic Botany, v. 86, n.3, p. 285-290. DOI: https://doi.org/10.1016/j. aquabot.2006.10.008.

Camargo L, Pellerin J, Panitz CMN. 2004. Derivation and aplication of algorism of 5 meters (image mask) for mangrove classification. Gayana, Concepcíon, v. 68, n. 2, p. 77-82. DOI:http://dx.doi.org/10.4067/S0717-65382004000200015.

Carvalho NM, Nakagawa J. 2000. Sementes: ciência, tecnologia e produção. 4.ed. 588p. Jaboticabal: FUNEP.

Dickson A, Leaf AL, Hosner JF. 1960. Quality appraisal of white spruce and white pine seedling stock in nurseries. Forest Chronicle, Mattawa, v. 36, p.10-13. DOI: https://doi.org/10.5558/tfc36010-1.

Finney W. 2011. Comparative growth and propagule viability of Louisiana-harvested black mangrove, Avicennia germinans. Thesis (Master of Science in Marine and Environmental Biology) - Nicholls State University, Thibodaux, LA (US). $34 \mathrm{p}$. 
Gonçalves JLM, Santarelli EG, Moraes Netto SP, Manara MP, Stape JL. 2000. Produção de mudas de espécies nativas: substrato, nutrição, sombreamento e fertilização. In: Nutrição e fertilização florestal. Piracicaba: IPEF.

Guerrero R, Guillen Castillo DA, Navas Duran MA. 1992. Determination of the natural regeneration capacity of four species in the swamp El Amatal and ex situ germination test of the black mangrove (Avicennia nitida J). El Salvador Univ., San Salvador (El Salvador). Facultad De Ciencias Agronomicas. Disponível em: http://agris.fao.org/agrissearch/search.do? recordID=SV19930026396.

Hossain M, Saha S, Salekin S, Al-Mamun A, Siddique MRH, Abdullah SMR. 2014. Salinity influence on germination of four importante Mangrove species of the Sundarbans, Bangladesh. Agriculture and Forestry, Podgorica, vol. 60, n. 2, p. 125135. DOI:https://www.researchgate.net/publication/263480282.

INMET. 2017. Consulta Dados da Estação Automática: Acaraú (CE). Disponível em http://www.inmet.gov.br/portal/ index.php?r=estacoes/estacoesAutomaticas. Acessado em 10 julho de 2017.

Kikuti AP, Menten JOM, Moraes MHD, Oliveira SRS. 2005. Interferência da assepsia em sementes de pimentão submetidas ao teste de envelhecimento acelerado. Revista Brasileira de Sementes, Londrina - PR, vol. 27, no 2, p.44-49. DOI: http:// dx.doi.org/10.1590/S0101-31222005000200007.

Machado ELM, Gonzaga APD, Macedo RLG, Venturin N, Gomes JE. 2006. Importância da avifauna em programas de recuperação de áreas degradadas. Revista Científica Eletrônica de Engenharia Florestal, Garça. Ano iv, número 07, ISSN 1678-3867.

Maia LP, Lacerda LD, Monteiro LHU, Souza GM. 2006. Atlas dos Manguezais do Nordeste do Brasil: Avaliação das Áreas de Manguezais dos Estados do Piauí, Ceará, Rio Grande do Norte, Paraíba e Pernambuco. SEMACE: Fortaleza.

Maguire JD. 1962. Speeds of germination-aid selection and evaluation for seedling emergence and vigor. Crop Science, Madison, v.2, p.176-177. DOI: http://dx.doi.org/10.2135/cropsci1962.0011183X000200020033x.

Meireles AJA, Cassola RS, Tupinambá SV, Queiroz LS. 2007. Impactos ambientais decorrentes das atividades da carciniculturaao longo do litoral cearense, Nordeste do Brasil. Revista de Geografia, Fortaleza, Universidade Federal do Ceará. Disponível em: https://www.researchgate.net/publication/237031619.

Muniz MFB, Silva LM, Blume E. 2007. Influência da assepsia e do substrato na qualidade de sementes e Mudas de espécies florestais. Revista Brasileira de Sementes, Londrina - PR, vol. 29, no 1, p.140-146. DOI: http://dx.doi.org/10.1590/ S0101-31222007000100019.

Oliveira VF. 2005. Influência do estresse hídrico e salino na germinação de propágulos de Avicennia schaueriana Stapf e Leechman ex Moldenke e Laguncularia racemosa (L.) Gaertn. f. 82 f. Dissertação (Mestrado em Botânica) Escola Nacional de Botânica Tropical, Instituto de Pesquisas Jardim Botânico do Rio de Janeiro. Rio de Janeiro.

Pedron FA, Menezes JP, Menezes NL. 2004. Parâmetros biométricos de fruto, endocarpo e semente de butiazeiro. Ciência Rural, Santa Maria, vol.34, n.2. DOI: http://dx.doi.org/10.1590/S0103-84782004000200040.

Pereira GA, Ribeiro BV, Marcílio HC, Santaella MB. 2009. Desinfestação e estabelecimento in vitro de explantes de bananeira 'IAC 2001' em diferentes concentrações de hipoclorito de sódio. Tecnologia \& Ciência Agropecuária, João Pessoa, v.3, n.2, p. 43-46. DOI: https://www.researchgate.net/publication/239554258. 
Pinho KC. 2012. Esterilização química de meio de cultura para micropropagação de Cana-de-Açúcar [Saccharum spp.]. 2012. 48 f. Dissertação (Mestrado em Ciências) - Universidade Federal Rural do Rio de Janeiro, Instituto de Biologia. Campos dos Goytacazes - RJ.

Pompei CS, Pifarre DV, Martínez MB, Dominguez JC, Monrabá JA. 2014. Estudio multidisciplinario del ecosistema manglar en la comunidad tradicional de Curral Velho: Análisis de los servicios ecosistémicos producidos por los manglares a partir de la percepción de la comunidad de Curral Velho. Ciencias Ambientales. Bellaterra. Disponível em: <https://ddd.uab.cat/pub/trerecpro/2014/hdl_2072_248363/PFC_BriansoVide.pdf>.

Purnobasuki H, Utami ESW. 2016. Seed germination of Avicennia marina (Forsk.) Vierh. by pericarp removal treatment. Biotropia, Indonésia, vol. 23, n. 2, p. 74 - 83. DOI: http://dx.doi.org/10.11598/btb.2016.23.2.349.

Rycka DJR, Robert EMR, Schmitz N, Stocken TV, Nitto DD, Dahdouh-Guebas F, Koedam N. 2012. Size does matter, but not only size: Two alternative dispersal strategies for viviparous mangrove propagules. Aquatic Botany, v. 103, p. 66-73. DOI: https://doi.org/10.1016/j.aquabot.2012.06.005.

Secretaria do Meio Ambiente. 2014. Manual de Orientação para Implantação de Viveiro de Mudas. São Paulo. Disponível em: http://www.ambiente.sp.gov.br/cea/2014/11/24/manual-de-orientacao-dara-implantacao-de-viveiro-de-mudas/.

Silva MAB, Bernini E, Carmo TMS. 2005. Características estruturais de bosques de mangue do estuário do rio São Mateus, ES, Brasil. Acta Botanica Brasilica, Belo Horizonte, v. 19, n. 3, p. 465-471. DOI: http://dx.doi.org/10.1590/S010233062005000300006.

Skarpaas O, Silverman EJ, Jongejans E, Shea K. 2011. Are the best dispersers the best colonizers? 5 Seed mass, dispersal and establishment in Carduus thistles. Evolutionary Ecology, v. 25, n. 1, p.155-169. DOI: 10.1007/s10682-010-9391-4.

Soares MLG, Chaves FO, Cavalcanti VF, Portugal AMM, Barbosa B. 2008. Caracterização das florestas de mangue do complexo estuarino de Caravelas (Bahia-Brasil). Boletim Técnico Cientifico, Tamandaré - PE, v. 16, n. 5, p. 23-41. Disponível em: https://www.researchgate.net/publication/256444396.

Sousa WP, Kennedy PG, Mitchell BJ. 2003. Propagule size and predispersal damage by insects affect establishment and early growth of mangrove seedlings. Oecologia, v.135, n.4, p.564-75. DOI:10.1007/s00442-003-1237-0.

Srey S, Jahid IK, Ha S. 2013. Biofilm formation in food industries: A food safety concern. Food Control, v. 31, n. 2, p. 572 - 585. DOI: https://doi.org/10.1016/j.foodcont.2012.12.001.

Turnbull LA, Rees M, Crawley MJ. 1999. Seed mass and the competition/colonization trade-off: a sowing experimente. Journal of Ecology, V. 87, n. 5, P. 899-912. DOI: https://doi.org/10.1046/j.1365-2745.1999.00405.x.

Waycott M, Duarte CM, Carruthers TJB, Orth RJ, Dennison WC, Olyarnik S, Calladine A, Fourqurean JW, Heck Jr. KL, Hughes AR, Kendrick GA, Kenworthy WJ, Short FT, Williams SL. 2009. Accelerating loss of seagrasses across the globe threatens coastal ecosystems. Proceedings of the National Academy of Sciences of the United States of America, Estados Unidos, vol. 106, n. 30, P. 12377-12381. DOI: https://doi.org/10.1073/pnas.0905620106. 